\title{
A COMPARISON OF PROPOFOL WITH SEVOFLURANE AND PROPOFOL ALONE FOR INDUCTION AND INTUBATION
}

\author{
Manjunath $C^{1}$, Madhu $R^{2}$
}

${ }^{1}$ Senior Specialist, Department of Anesthesia, Aster CMI Hospital, Bangalore.

${ }^{2}$ Assistant Professor, Department of Anesthesia, MVJ MC and RH, Bangalore.

ABSTRACT: STUDY OBJECTIVE: We aimed to study propofol with sevoflurane and propofol alone in evaluating intubating conditions, hemodynamic response during induction and intubation and induction side effects in adult patients undergoing various elective surgical procedures without muscle relaxants.

DESIGN: Prospective randomized study.

SETTING: Operation theatre of a teaching institute.

PATIENTS: The study population consists of 60 ASA I \& II, non-obese, adult patients aged between 20-40yrs coming for elective surgical procedures under General Anaesthesia and had Mallampatti class I airway anatomy, 30 of these patients receive propofol alone-"GROUP A" and 30 of who receive propofol with sevoflurane-“GROUP B".

MEASUREMENTS AND RESULTS: The heart rate, systolic blood pressure, diastolic blood pressure and mean arterial pressure before and after induction and post-intubation at 1, 3 and 5 minutes were recorded. Time to induction in seconds (Start of anaesthetic until loss of eye lash reflex), induction side effects like breath holding, cough, excitatory movements, laryngospasm and others (Bradycardia, hypoxia, hyperthermia, hypothermia and injection site pain) were noted.

Intubating conditions were better in Group-B than in Group-A, Group-B patients had significantly had more clinically acceptable intubating conditions than Group-A. There was no significant difference in heart rate after induction and intubation between the two groups, except $3 \mathrm{~min}$ after intubation in Group-A there is significantly low heart rate. There was significant in reduction in systolic blood pressure after induction and intubation in Group-A, however there was no significant difference in diastolic blood pressure and mean arterial pressure between two groups. Induction time is significantly less in Group-A patients when compared to Group-B patients and there was no significant difference in induction side effects between two groups.

CONCLUSION: Combination of inhalational $4 \%$ sevoflurane with IV propofol $1.5 \mathrm{mg} / \mathrm{kg}$ is superior to IV propofol $3 \mathrm{mg} / \mathrm{kg}$ with respect to quality of intubation and less significance with respect to hemodynamic response during induction and intubation in adult patients undergoing various elective surgical procedures without muscle relaxants.

KEYWORDS: Induction , Intubation, Sevoflurane, Propofol, Hemodynamics.

HOW TO CITE THIS ARTICLE: Manjunath C, Madhu R. "A Comparison of Propofol with Sevoflurane and Propofol Alone for Induction and Intubation". Journal of Evolution of Medical and Dental Sciences 2015; Vol. 4, Issue 92, November 16; Page: $15717-15721$, DOI: $10.14260 /$ jemds/2015/2267.

INTRODUCTION: Endotracheal intubation is the most important and crucial step during administration of general anaesthesia. ${ }^{1}$ The ease with which endotracheal intubation is achieved depends on technical proficiency, depth of anaesthesia and degree of muscle relaxation. Intubation in anaesthesia using short-acting hypnotic drug is frequently facilitated by the simultaneous administration of a depolarizing muscle relaxant such as succinylcholine. However, succinylcholine administration may be associated, at times, with side effects such as postoperative myalgia, malignant hyperthermia, masseter spasm, histamine release, anaphylaxis, hyperkalemia, cardiac arrhythmias and increase in intracranial or intraocular pressure. These side effects have spurred research into the development of a nondepolarizing drug with short onset of action.

Financial or Other, Competing Interest: None.

Submission 31-10-2015, Peer Review 01-11-2015,

Acceptance 07-11-2015, Published 13-11-2015.

Corresponding Author:

Dr. Manjunath $C$

No. 56, $1^{\text {st }}$ Floor, $1^{\text {st }}$ Cross, $5^{\text {th }}$ Main, Ags Colony,

Anandanagar, Bangalore-560024.

E-mail: docmanju@rediffmail.com

DOI:10.14260/jemds/2015/2267.
Even the use of non-depolarizing relaxants may be associated with undesirable effects such as prolonged neuromuscular blockage, the need to reverse neuromuscular blockade, or the inability to reverse the paralysis quickly if airway management via mask or tracheal intubation is not possible. For these reasons, a method of providing good intubating condition rapidly without muscle relaxants has been sought. ${ }^{2-13}$ Propofol in combination with short-acting opioids such as fentanyl, alfentanil and remifentanil may provide adequate conditions for laryngoscopy and tracheal intubation without using muscle relaxants. ${ }^{13,14}$

Such a technique is of value in particular situations in which muscle relaxants have to be avoided (Myopathies, known allergic reactions to muscle relaxants) or in cases where succinylcholine is contraindicated (Hyperkalemia, burns, plasma cholinesterase deficiency, penetrating eye injury). Propofol is a short-acting intravenous anaesthetic with high lipid solubility and short elimination half-life. ${ }^{15}$ However, propofol has been associated with several adverse effects, including hypotension, apnea, pain on injection, and excitatory patient movements. ${ }^{16}$ Pain on injection can be avoided if propofol is administered after inhalation induction of anaesthesia. Potent inhalation agents can be used as an alternative to facilitate tracheal intubation. 
Sevoflurane with its relatively pleasant smell, low airway irritability and low blood-gas solubility allowing smooth and more rapid induction and recovery, Sevoflurane as compared with propofol, has the advantage of providing better hemodynamic stability and a smoother transition to the maintenance phase without a period of apnea. ${ }^{17}$ Combination of lesser percentage of halothane with propofol has been studied and concluded that combination of inhalational agent and propofol is ideal for intubation in children. ${ }^{18}$ Sevoflurane $8 \%$ can be used as an alternative to facilitate tracheal intubation. ${ }^{19}$ but it is not cost effective. Combination of Sevoflurane $8 \%$ and propofol $1.5 \mathrm{mg} / \mathrm{kg}$ has been tried for Laryngeal Mask Airway insertion. ${ }^{17}$

Induction of anaesthesia with a combination of lesser dose of propofoland lesser percentage of sevoflurane with opioid pre-medication may optimize the inserting conditions of endotracheal tube and decrease the side effects that may follow with propofol alone. ${ }^{17}$ Hence an attempt was made with a combination of lesser percentage of Sevoflurane with reduced dosage of Propofol for intubation with endotracheal tube to evaluate intubation conditions, hemodynamic response during induction and intubation and induction side effects without muscle relaxants in adult patients of age group 20-40yrs undergoing various elective surgical procedures.

MATERIALS AND METHODS: This study was undertaken after approval by our institution Research and Ethics committee and obtaining patient's written informed consent, patients were randomized into two groups of 30 each, i.e. Group A and Group B. This is a prospective randomized study. The study population consists of 60 ASA I \& II, non-obese, adult patients aged between 20-40yrs coming for elective surgical procedures under General Anaesthesia and had Mallampatti class I airway anatomy. Patients were excluded who were unwilling, had history or evidence of difficult airway, malignant hyperthermia, allergy to volatile anaesthetics or propofol, patients who on MAO-inhibitors and patients with body mass index more than 1.5 times normal.

A thorough pre-anaesthetic evaluation was conducted on the day before surgery. Detailed history and cardiorespiratory examination was carried out in all patients. All relevant investigations were done. Nil per oral status for a minimum of $6 \mathrm{hrs}$ was advised. On the day of surgery, after arrival of patient to the operation theatre pulse-oxymeter, ECG, and non-invasive blood pressure monitors were connected. The baseline heart rate, systolic blood pressure, diastolic blood pressure and mean arterial pressure were recorded.

After doing a thorough cockpit drill of continuous flow anaesthesia machine and availability of emergency drugs with $\mathrm{ETCO}_{2}$ monitor, an intravenous line with Ringer's Lactate was secured using either 18G or 20G intravenous cannula. All patients were per-medicated with IV fentanyl $2 \mu \mathrm{g} / \mathrm{kg}$, IV midazolam $1 \mathrm{mg} \&$ IV Glycopyrrolate $0.2 \mathrm{mg} 5 \mathrm{~min}$ before induction. All patients were pre-oxygenated with $100 \% \mathrm{O}_{2}$ for $3 \mathrm{~min}$. Anaesthesia was then induced in Group-A patients by $67 \% \mathrm{~N}_{2} \mathrm{O}$ in $\mathrm{O}_{2}$ and IV propofol $3 \mathrm{mg} / \mathrm{kg}$ injected over 30s. Group-B patients were induced by mask with sevoflurane starting at $0.5 \%$ and incrementally increased to
$4 \%$ inhaled concentration with $67 \%$ nitrous oxide in oxygen at a total gas flow of 8 liters $/ \mathrm{min}$ and IV propofol $1.5 \mathrm{mg} / \mathrm{kg}$ injected over $15 \mathrm{~s}$ and tracheal intubation was attempted at 240 s after the start of induction in both groups.

Lignocaine $0.2 \mathrm{mg} / \mathrm{kg}$ added to propofol to prevent pain on injection. The heart rate, systolic blood pressure, diastolic blood pressure and mean arterial pressure before and after induction and post-intubation at 1, 3 and 5 minutes were recorded. Time to induction in seconds (Start of anaesthetic until loss of eye lash reflex), induction side effects like breath holding, cough, excitatory movements, laryngospasm and others (Bradycardia, hypoxia, hyperthermia, hypothermia and injection site pain) were noted. ${ }^{19}$

Tracheal intubation was performed using appropriately sized endo-tracheal tube. Intubating conditions were assessed by anaesthesiologist who performed intubation using Copenhagen Consensus Conference (CCC) score.19 which graded the quality of tracheal intubation according to ease of laryngoscopy, position of the vocal cords, cough and movement of the limbs. Supplementation of endotracheal intubation with IV succinylcholine noted.

RESULTS: Statistical analysis of age, sex and weight distribution was done by using student's unpaired-t test. A pvalue of less than 0.05 was regarded as significant. Both groups were found to be statistically similar with respect to age, sex and weight distribution. ASA grade is statistically similar between two groups with $\mathrm{P}=0.688$.

\begin{tabular}{|c|c|c|}
\hline $\begin{array}{c}\text { Time to } \\
\text { Induction (Sec) }\end{array}$ & $\begin{array}{c}\text { Group A } \\
(\mathbf{n = 3 0 )}\end{array}$ & $\begin{array}{c}\text { Group B } \\
(\mathbf{n = 3 0 )}\end{array}$ \\
\hline $1-100$ & $30(100.0 \%)$ & 0 \\
\hline $101-200$ & 0 & $29(96.7 \%)$ \\
\hline$>200$ & 0 & $1(3.3 \%)$ \\
\hline Total & $\mathbf{3 0}(\mathbf{1 0 0 . 0} \%$ & $\mathbf{3 0}(\mathbf{1 0 0 . 0} \%)$ \\
\hline Mean $\mathbf{\text { SD }}$ & $\mathbf{3 9 . 8 0 \pm 8 . 1 0}$ & $\mathbf{1 5 6 . 0 7} \pm \mathbf{2 1 . 5 8}$ \\
\hline \multicolumn{2}{|c|}{ Table 1: Time to Induction (Seconds) } \\
\hline
\end{tabular}

Induction time is significantly less in Group A patients $(39.80 \pm 8.10)$ when compared with Group B patients (156.07 \pm 21.58$),(\mathrm{p}<0.001)$.

\begin{tabular}{|c|c|c|c|}
\hline $\begin{array}{c}\text { Induction Side } \\
\text { Effects }\end{array}$ & $\begin{array}{c}\text { Group A } \\
(\mathbf{n = 3 0 )}\end{array}$ & $\begin{array}{c}\text { Group B } \\
\text { (n=30) }\end{array}$ & P value \\
\hline Breath holding & $3(10.0 \%)$ & 0 & 0.237 \\
\hline Cough & $6(20.0 \%)$ & $2(6.7 \%)$ & 0.254 \\
\hline $\begin{array}{c}\text { Excitatory } \\
\text { movements }\end{array}$ & $3(10.0 \%)$ & $1(3.3 \%)$ & 0.612 \\
\hline Laryngospasm & 0 & 0 & - \\
\hline Others & 0 & 0 & - \\
\hline \multicolumn{2}{|r|}{ Table 2: Induction Side Effects } \\
\hline
\end{tabular}

Both groups were found to be statistically similar with respect to breath holding, cough, excitatory movements, laryngospasm and other induction side-effects.

\begin{tabular}{|c|c|c|}
\hline $\begin{array}{c}\text { Number of } \\
\text { Attempts }\end{array}$ & $\begin{array}{c}\text { Group A } \\
(\mathbf{n = 3 0 )}\end{array}$ & $\begin{array}{c}\text { Group B } \\
(\mathbf{n = 3 0 )}\end{array}$ \\
\hline 1 & $23(76.7 \%)$ & $29(96.7 \%)$ \\
\hline 2 & $5(16.7 \%)$ & $1(3.3 \%)$ \\
\hline 3 & $2(6.6 \%)$ & 0 \\
\hline \multicolumn{3}{|c|}{ Table 3: Number of Attempts } \\
\hline
\end{tabular}


$23.3 \%$ patients in group A required 2 or 3 attempts for intubation when compared with $3.3 \%$ in group $B$, which is highly significant $(\mathrm{p}<0.001)$.

\begin{tabular}{|c|c|c|}
\hline $\begin{array}{c}\text { Tracheal intubation } \\
\text { supplemented with } \\
\text { succinylcholine }\end{array}$ & $\begin{array}{c}\text { Group A } \\
\text { (n=30) }\end{array}$ & $\begin{array}{c}\text { Group B } \\
\text { (n=30) }\end{array}$ \\
\hline No & $26(86.7 \%)$ & $30(100.0 \%)$ \\
\hline Yes & $4(13.3 \%)$ & 0 \\
\hline \multicolumn{2}{|c|}{ Table 4:Tracheal Intubation } \\
\hline \multicolumn{2}{|c|}{ Supplemented with Succinylcholine } \\
\hline
\end{tabular}

None of the patients in Group B required succinylcholine supplementation to achieve intubation, when compared with $13.3 \%$ in Group A, which is not significant ( $p=0.112$ ).

\begin{tabular}{|c|c|c|c|}
\hline $\begin{array}{c}\text { Heart } \\
\text { Rate } \\
\text { (bpm) }\end{array}$ & $\begin{array}{c}\text { Group A } \\
(\mathbf{n}=\mathbf{3 0})\end{array}$ & $\begin{array}{c}\text { Group B } \\
(\mathbf{n}=\mathbf{3 0})\end{array}$ & P value \\
\hline $\begin{array}{c}\text { Pre- } \\
\text { Induction }\end{array}$ & $90.97 \pm 9.86$ & $89.13 \pm 13.63$ & $\mathrm{t}=0.597 ; \mathrm{p}=0.553$ \\
\hline $\begin{array}{c}\text { Post- } \\
\text { Induction }\end{array}$ & $81.97 \pm 8.66$ & $86.73 \pm 13.34$ & $\mathrm{t}=1.642 ; \mathrm{p}=0.106$ \\
\hline $\begin{array}{c}\text { 1 min after } \\
\text { intubation }\end{array}$ & $87.9 \pm 8.47$ & $91.43 \pm 13.42$ & $\mathrm{t}=1.220 ; \mathrm{p}=0.227$ \\
\hline $\begin{array}{c}\text { 3 min after } \\
\text { intubation }\end{array}$ & $87.33 \pm 7.57$ & $93.67 \pm 13.26$ & $\mathrm{t}=2.272 ; \mathrm{p}=0.027$ \\
\hline $\begin{array}{l}5 \text { min after } \\
\text { intubation }\end{array}$ & $87.67 \pm 8.1$ & $89.23 \pm 13.33$ & $\mathrm{t}=0.550 ; \mathrm{p}=0.584$ \\
\hline \multicolumn{4}{|c|}{ Table 5: Comparison of Heart Rate (bpm) } \\
between Two Groups
\end{tabular}

There was no significant difference in heart rate after induction and post-intubation between the two groups except $3 \mathrm{~min}$ after intubation which was significant $(\mathrm{p}=0.027)$.

\begin{tabular}{|c|c|c|c|}
\hline $\begin{array}{c}\text { MAP } \\
(\mathbf{m m} \text { Hg) }\end{array}$ & $\begin{array}{c}\text { Group A } \\
(\mathbf{n = 3 0})\end{array}$ & $\begin{array}{c}\text { Group B } \\
\mathbf{( n = 3 0 )}\end{array}$ & P value \\
\hline $\begin{array}{c}\text { Pre- } \\
\text { Induction }\end{array}$ & $96.1 \pm 8.05$ & $93.17 \pm 8.12$ & $\mathrm{t}=1.405 ; \mathrm{p}=0.165$ \\
\hline $\begin{array}{c}\text { Post- } \\
\text { Induction }\end{array}$ & $85.33 \pm 8.18$ & $90.07 \pm 7.66$ & $\mathrm{t}=2.314 ; \mathrm{p}=0.024^{*}$ \\
\hline $\begin{array}{c}\text { 1 min after } \\
\text { intubation }\end{array}$ & $91.77 \pm 7.79$ & $94.50 \pm 7.74$ & $\mathrm{t}=1.363 ; \mathrm{p}=0.178$ \\
\hline $\begin{array}{c}\text { 3 min after } \\
\text { intubation }\end{array}$ & $94.00 \pm 8.38$ & $95.10 \pm 7.65$ & $\mathrm{t}=0.531 ; \mathrm{p}=0.597$ \\
\hline $\begin{array}{c}\text { 5 min after } \\
\text { intubation }\end{array}$ & $92.20 \pm 7.96$ & $93.63 \pm 7.77$ & $\mathrm{t}=0.705 ; \mathrm{p}=0.483$ \\
\hline
\end{tabular}

Table 6: Comparison of MAP ( $\mathrm{mm} \mathrm{Hg}$ ) between Two Groups

There was no significant difference in mean arterial pressure between the two groups following intubation, but there was a significant difference in mean arterial pressure following induction $(p=0.024)$.

DISCUSSION: Laryngoscopy and tracheal intubation are essential skills associated with practice of anaesthesia. The drugs should be combined in such a way that it produces unconsciousness, analgesia and muscle relaxation without compromising hemodynamic stability, at the same time providing best intubating conditions. ${ }^{4}$ usually a combination of hypnotic agent, opioid and a neuromuscular blocking agent is used. Over past few years, several factors have led researchers to ignore neuromuscular blocking agents for tracheal intubation. The driving force were introduction of propofol, short acting opioids and sevoflurane in clinical practice. Propofol not only suppresses upper airway reflexes and pressor response to laryngoscopy and tracheal intubation but also provides faster recovery of consciousness, possess anti-emetic action and reduces incidence of airway complications. ${ }^{20}$

Although, succinylcholine is the gold standard to provide adequate relaxation because of its rapid onset within $30-60$ s and quick metabolism, routine use of this drug has been questioned following several reports of cardiac arrest in young children. In addition it has many other potential problems: myalgia, cardiac arrhythmias, elevated intraocular and intracranial pressure, hyperkalemia, malignant hyperthermia and prolonged apnea.20 Non-depolarizing neuromuscular agents are alternative but are slower in onset and have a longer duration of action.

Sevoflurane a new inhalational agent with low bloodgas solubility and a relatively pleasant odour produces rapid induction and recovery. It causes less myocardial depression and cardiac arrhythmias than halothane. ${ }^{21}$ In our study, we used fentanyl $2 \mu \mathrm{g} / \mathrm{kg}$ intravenously, 5 min before induction, because in addition to analgesia, it also blunts pressor response against laryngoscopy and intubation. Fentanyl also has anti tussive action. Katohet al. ${ }^{22}$ suggested that fentanyl blocks afferent nerve impulses arising from stimulation of the pharynx, larynx and lungs during intubation.

The peak effect of propofol from the time of administration of drug was around 90-100s, Mc Keating et al. ${ }^{3}$ study showed that it is possible to perform laryngoscopy safely and smoothly at 120 s after induction with propofol. Therefore we took 240s as a fixed time interval from the start of induction to intubation in Group A patients (IV propofol $3 \mathrm{mg} / \mathrm{kg}$ ). The use of fixed time interval tests an easily reproducible technique, independent of subjective assessments of depth of anaesthesia.

Swadia VN et al. ${ }^{23}$ and Bithal PK et al. ${ }^{24}$ had found significantly greater time for tracheal intubation with sevoflurane i.e. $(242.2 \pm 52.67 \mathrm{~s})$ and $(325.93 \pm 44.02 \mathrm{~s})$ respectively. This difference was not only because of different clinical end points but also a different induction technique in which sevoflurane concentration was increased incrementally and ventilation was not assisted manually. In a study by Erhan E et al. ${ }^{5}$ clinically acceptable intubating conditions were found in $93.3 \%, 66.7 \%$ and $40 \%$ in patients receiving propofol, thiopental or etomidate respectively. Patients receiving propofol found to have less severe coughing after intubation when compared to thiopental or etomidate.

In Thwaiteset al. ${ }^{25}$ study, all children could successfully be intubated with $8 \%$ sevoflurane in nitrous oxide and oxygen at 150 s. $91 \%$ children had excellent intubating conditions and $9 \%$ had good intubating conditions. They demonstrated that $8 \%$ sevoflurane with nitrous oxide in oxygen can provide acceptable intubating conditions at $150 \mathrm{~s}$.

In our study, tracheal intubation was accomplished in $100 \%$ of patients in Group B, $93.3 \%$ of those patients had acceptable intubating conditions when compared with $73.3 \%$ in Group A, which is highly significant $\left(\chi^{2}=4.320 ; \mathrm{p}<0.001\right)$. $86.7 \%$ of patients had no cough in Group B, compared with $56.7 \%$ in group A. 
Coughing was significantly associated more with Group A $(p=0.037)$. Limb movements were significantly more in Group A compared to Group B. None of the patients in Group $B$ required succinylcholine supplementation to achieve intubation. $96.7 \%$ of patients were intubated at first attempt in Group B when compared with 76.7\% in Group A. Number of attempts were significantly less in Group B $(p<0.001)$. In Group A $13.3 \%$ of patients required succinylcholine supplementation to achieve intubation because of vocal cords movement, coughing and excessive limb movements.

Only $76.7 \%$ of patients intubated at first attempt and remaining $23.3 \%$ required multiple attempts. During induction, $10 \%$ of patients in Group A had breath holding, $20 \%$ had cough and $10 \%$ had excitatory movements, which is not significant. Induction time in Group B patients were $156.07 \pm 21.58$ s, when compared with Group A $(39.80 \pm 8.10)$. Induction time were more in Group $B$ patients $(\mathrm{t}=27.629 ; \mathrm{p}<0.001)$. In Swadia et al. ${ }^{23}$ study anaesthesia was induced with $60 \%$ nitrous oxide in oxygen and incremental increase in concentration of sevoflurane from 1-7\%.

Time interval from application of facemask to intubation was $242 \pm 52.67 \mathrm{~s}$. $80 \%$ of children had excellent intubating conditions. $16 \%$ had tachycardia, $8 \%$ had bradycardia and $80 \%$ had hypotension. Complications like laryngospasm, bronchospasm were not observed. In present study there was reduction in heart rate, systolic blood pressure, diastolic blood pressure and mean arterial pressure in Group-A patients after induction and intubation when compared with pre-induction values.

However, there was no significant difference among these parameters when compared with pre-induction values in Group B patients. Thus propofol decreased both heart rate and blood pressure, which indicates there was decrease in cardiac output. Similar results were found in other studies, Srivastava $U$ et al. ${ }^{13}$ found significant decrease in HR and arterial pressure from baseline in children given propofol and fentanyl. Steyn et al. ${ }^{26}$ observed a no change in HR but found a significant fall in MAP after induction and following intubation with a dose combination of propofol $3 \mathrm{mg} / \mathrm{kg}$ and alfentanil $15 \mu \mathrm{g} / \mathrm{kg}$ in children.

In Swadiaet al. ${ }^{23}$ study sevoflurane group $16 \%$ patients, developed tachycardia, $8 \%$ had bradycardia and $80 \%$ had hypotension. In Bithal PK et al. ${ }^{24}$ study HR was significantly high in the sevoflurane group, during post-induction and immediate post-intubation and $1 \mathrm{~min}$ post-intubation. MAP also increased but slightly from baseline. In our study there was no significant difference in heart rate after induction and intubation between the two groups, except $3 \mathrm{~min}$ after intubation, where heart rate is significantly low in Group A $(87.33 \pm 7.57)$ when compared with Group B (93.67 \pm 13.26$)$, $(\mathrm{p}=0.027)$.

There was significant reduction in systolic blood pressure after induction and intubation in Group A patients when compared with Group B patients. However, there was no significant difference in diastolic blood pressure and mean arterial pressure between two groups, except mean arterial pressure being low in Group A following induction ( $p=0.024)$.

CONCLUSION:We concluded that combination of inhalational $4 \%$ sevoflurane with IV propofol $1.5 \mathrm{mg} / \mathrm{kg}$ is superior to IV propofol $3 \mathrm{mg} / \mathrm{kg}$ with respect to quality of intubation and less significance with respect to hemodynamic response during induction and intubation in adult patients undergoing various elective surgical procedures without muscle relaxants and also this combination is cost effective. This combination can also be attempted for anticipated difficult intubation.

\section{BIBLIOGRAPHY:}

1. Bithal PK, Soudagar A, Paul M, Bali A. Comparison of halothane with sevoflurane inhalation in children for tracheal intubation. Ind J Anaesth 2000; 44: 47-54.

2. Woods AW, Allam S. Tracheal intubation without the use of neuromuscular blocking agents. Br J Anaesth 2005; 94: 150-158.

3. Mc Keating K, Bali IM, Dundee JW. The effects of thiopentone and propofol on upper airway integrity. Anaesthesia 1988; 43: 638-640.

4. Francois D. Tracheal intubation: unconsciousness, analgesia and muscle relaxation.

Can J Anesth 2003; 50: 99-103.

5. Erhan E, Ugur G, Gunusen I, Alper I, Ozyar B. Propofolnot thiopental or etomidate-with remifentanil provides adequate intubating conditions in the absence of neuromuscular blockade.

Can J Anesth 2003; 50: 108-115.

6. Mc Neil IA, Culbert B, Russell I. Comparison of intubating conditions following propofol and succinylcholine with propofol and remifentanil $2 \mu / \mathrm{kg}$ or $4 \mu / \mathrm{kg}$. Br J Anaesth 2000; 85: 623-625.

7. Alexander R, Olufolabi AJ, Booth J, El-moalem HE, Glass PS. Dosing study of remifentanil and propofol for tracheal intubation without the use of muscle relaxants. Anaesthesia 1999; 54: 1037-1040.

8. Warner MA, Warner MF, Weber JG. Clinical significance of pulmonary aspiration during the perioperative period. Anesthesiology 1993; 78: 56-62.

9. Bevan DR, Donati F, Kopman AF. Reversal of neuromuscular blockade.

Anesthesiology 1992; 77: 785-805.

10. Glass PS. Anesthetic drug interactions: an insight into general anesthesia-its mechanism and dosing strategies. Anesthesiology 1998; 88: 5-6.

11. Dexter F, Gan TJ, Naguib M, Lubarsky DA. Cost identification analysis for succinylcholine. AnesthAnalg 2001; 92: 693-699.

12. Iamaroon A, Pitimana-aree S, Prechawai C, Anusit J, Somcharoen K, Chaiyaroj O. Endotracheal intubation with thiopental/succinylcholine or sevoflurane-nitrous oxide anesthesia in adults: A comparative study. AnesthAnalg 2001; 92: 523-528.

13. Srivastava U, Kumar A, Gandhi NK, Saxena S, Agarwal S. Comparison of propofol and fentanyl with thiopentone and suxamethonium for tracheal intubation in children. Ind J Anaesth 2001; 45: 263-266.

14. Taha S, Siddik-Sayyid S, Alameddine M, Wakim C, Dahabra C, Moussa A, Khatib M, Baraka A. Propofol is superior to thiopental for intubation without muscle relaxants. Can J Anesth 2005; 52: 249-253. 
15. Hannallah RS, Britton JT, Schafer PG, Patel RI, Norden JM. Propofolanaesthesia in paediatric ambulatory patients: A comparison with thiopentone and halothane. Can J Anaesth 1994; 41: 12-18.

16. Abdel-Halim JMK, Azer MS, El-Awady GA. Comparison of induction and recovery characteristics of sevoflurane, halothane and propofol in pediatric outpatients. Journal of the Egyptian Nat. Cancer Inst 2002; 14: 319-323.

17. Sayyid SMS, Aouad MT, Taha SK, Daaboul DG, Deeb PG, Massouh FM, Muallem MRA, Baraka AS. A comparison of sevoflurane-propofol versus sevoflurane or propofol for laryngeal mask airway insertion in adults. AnesthAnalg 2005; 100: 1204-1209.

18. Hansen D, Schaffartzik W, Dopjans D, Heitz E, Striebel HW. Halothane-propofolanaesthesia for tracheal intubation in young children.

Br J Anaesth 1997; 78: 366-369.

19. Jellish WS, Lien CA, Fontenot HJ, Hall R. The comparative effects of sevoflurane versus propofol in the induction and maintenance of anesthesia in adult patients. AnesthAnalg 1996; 82: 479-485.

20. Akhilesh Gupta, Ranvinder Kaur, Rohit Malhotra, Suniti Kale. Comparative evaluation of different doses of propofol preceded by fentanyl on intubating conditions and pressor response during tracheal intubation without muscle relaxants. PaediatricAnaesthe 2006; 16: 399-405.
21. Priya V, Divatia JV, Dasgupta D. A comparison of propofol versus sevoflurane for laryngeal mask airway insertion. Ind J Anaesth 2002; 46: 31-34.

22. Katoh T, Nakajima Y, Moriwaki G, Kobayashi S, Suzuki A, Iwamoto T, Bito H, Ikeda K. Sevoflurane requirements for tracheal intubation with and without fentanyl. Br J Anaesth 1999; 82(4): 561-565.

23. Swadia VN, Mamta GP. Comparison of induction and intubation characteristics of sevoflurane and halothane in paediatric patients. Ind J Anaesth 2001; 45(4): 294 297.

24. Pramod Kumar Bithal, AtlafSoudagar, Mallika Paul, Ayham Bali. Comparison of halothane with sevoflurane inhalation in children for tracheal intubation. Ind J Anaesth 2000; 44: 47-54.

25. Thwaites AJ, Edmends S, Tomlinson AA, Kendall JB, Smith I. Double-blind comparison of sevofluranevspropofol and succinylcholine for tracheal intubation in children. Br J Anaesth 1999; 83: 410-414.

26. Steyn MP, Quinn AM, Gillespie JA, Miller DC, Best CJ, Morton NS. Tracheal intubation without neuromuscular block in children. Br J Anaesth 1994; 72: 403-406. 